\title{
Research on the Design and Implementation of Middle School Physical Education Curriculum Based on the Process Model
}

\author{
Zeng Li ${ }^{*}$, Binbin Zhu' ${ }^{2}$ \\ ${ }^{1}$ Zhejiang Anji Senior High School, Huzhou 313300, Zhejiang Province, China \\ ${ }^{2}$ Huzhou Fourth Middle School Education Group, Huzhou 313000, Zhejiang Province, China \\ *Corresponding author: Zeng Li, 261134041@qq.com
}

Copyright: () 2022 Author(s). This is an open-access article distributed under the terms of the Creative Commons Attribution License (CC BY 4.0), permitting distribution and reproduction in any medium, provided the original work is cited.

\begin{abstract}
For a long time, the education work in China has been deeply affected by the target model. With the development of the times and the continuous reform of education, the impact of process model on education has become increasingly prominent. It does not only give full play to the internal value of the curriculum content, but also cultivate students' personality and subjectivity. Taking the middle school physical education curriculum design as an example, this paper explores the practical application of process model for reference.
\end{abstract}

Keywords: Process model; Middle school physical education; Curriculum design; Implementation

Online publication: January 24, 2022

\section{Introduction}

In middle school physical education, with the rise of humanism, the human standard of physical education has gradually attracted people's attention. At the same time, it has also placed more importance on the process model. The traditional target model has many defects and deficiencies in its implementation, but the process model can make up for these deficiencies and provide a new idea for the teaching of physical education. Teachers can flexibly choose the teaching content while taking into consideration of the actual situation, so as to give full play to the internal value of teaching content and cultivate students' personality and subjectivity.

\section{Overview of the process model}

The process model mainly describes in detail the teaching methods to be adopted, the contents to be learned, and the inherent standards of relevant activities in the process of curriculum design. Moreover, the development of the curriculum is not formulated according to a certain fixed goal and then evaluated, but rather, a continuous and dynamic process. The advantages of the process model include the following points: first, it pays attention to the general objectives and procedural principles, which is different from the previous target model; second, in curriculum development and design, the role and value of teachers are more emphasized; third, it emphasizes process education. 
3. The necessity of applying the process model in middle school physical education curriculum design

\subsection{Mobilizes and stimulates students' interest in learning}

At present, the physical education curriculum design in middle schools basically focuses on the target model and pays attention to students' mastery of relevant physical education skills. However, in foreign countries, it is based on the process model. One of the purposes of physical education is to mobilize and stimulate students' interest in learning as well as cultivate lifelong sports consciousness among students. Taking dribbling in basketball as an example, in domestic physical education, teachers would explain and demonstrate the technique by themselves; then, students would imitate, and the teachers would correct them. In this way, students can master the skill. Such a single and rigid teaching method enables students to master certain sports skills, but it virtually extinguishes students' interest in learning the sport, which is not conducive to the cultivation of lifelong sports consciousness. Under the process model, the teaching is mainly based on the students' understanding. Students may not master the relevant sports skill, but they would be able to experience the fun in sports, which is very helpful for the cultivation of students' lifelong sports consciousness ${ }^{[1]}$.

\subsection{Fully respects students' dominance in the classroom}

The traditional concept of education also has a direct impact on the concept of school physical education. In China, as physical education has been affected by the target model for a long time, it often neglects the cultivation of students' personality and weakens their dominance in classroom. Compared with other disciplines, physical education is beneficial in cultivating students' personality, but the reality is often the opposite. Under the target model, students tend to imitate their teachers' actions mechanically, thus lacking the integration of emotion and thought. Through the process model, they can effectively make up for the defects and deficiencies of the target model, fully respect students' dominance in classroom, cultivate students' thinking skill, personality, and creativity, as well as develop students' potential, so that students can fully express their different views, which is very helpful for the all-round and healthy development of their bodies and minds ${ }^{[2]}$.

\subsection{Gives full play to the internal value of the teaching content}

Internal value mainly refers to the potential value that is not easily discovered by others. No matter what course, it has internal value and external value. The physical education curriculum design based on the target model basically takes goal formulation as the core and gives full play to the external value of the teaching content. As an essential and important discipline, compared with other disciplines, physical education does not only emphasize on people-oriented value, but also pay more attention to students' emotional experience. Its ultimate goal is to promote an all-round and healthy development. Through the practical application of process model in physical education curriculum design, it is possible to give full play to the internal value of the teaching content. When the teaching content triggers students' thinking and brings happiness as well as satisfaction, it can then realize its internal value ${ }^{[3]}$.

\section{Application of the process model in middle school physical education curriculum design}

Firstly, under the traditional target model, the design of middle school physical education curriculum usually has higher requirements for teachers' professional skill level and knowledge reserve. However, under the process model, teachers are not only required to have higher professional skill level and knowledge reserve, but also their understanding ability, thinking ability, grasp ability, and organization ability. An excellent and qualified physical education teacher should not only improve students' physical quality and accurately convey relevant skills to students, but also inspire their intelligence. Physical 
education curriculum based on the process model can cultivate and exercise students' ideological ability. However, according to the actual development situation, many middle school physical education teachers do not meet the above requirements, thus hindering and limiting the role and value of the process model in middle school physical education curriculum design.

Secondly, the process model emphasizes the process of curriculum design and does not pay as much attention to results as the target model does, which has a certain impact on the realization of curriculum teaching objectives; however, educational results are uncertain. In addition, the curriculum evaluation standard is flawed, so it is difficult to supervise and evaluate physical education teaching under the process model. In view of the above situation, an evaluation method based on the process model can be constructed. In the process of evaluating teachers, students can evaluate teachers' control over classroom and their own classroom experience through questionnaires. In addition, teachers should establish correct curriculum views. Only in this way can they have firm faith in curriculum design, rather than following suit.

Finally, the middle school physical education curriculum design based on the process model pays more attention to the classroom teaching process, which causes difficulty in completing many quantitative teaching objectives. Affected by exam-oriented education, the completion of teaching objectives in physical education classroom teaching based on the process model is far less than the target model. Therefore, in future educational practice, there is a need to find a balance between improving the efficiency of classroom teaching and the application of the process model, so as to give full play to its application value ${ }^{[4]}$.

\section{Design and implementation of middle school physical education curriculum based on the process model}

\subsection{Design}

In order to apply the process model to the physical education curriculum design in middle schools, first of all, it is imperative to pay attention to the overall structure of the curriculum, based on the physical education teaching content with rich connotation and value. Second, the emphasis should be on the curriculum design and implementation process. Third, it is necessary to flexibly organize teaching while taking into consideration of classroom teaching and the actual situation of students. Under the target model, in preparation for classroom teaching, teachers generally prepare in advance and focus on the goal, which greatly weaken the creativity and flexibility of classroom teaching. Physical education classroom teaching based on the process model requires teachers to flexibly organize teaching while taking into consideration of classroom teaching and the actual situation of students. Taking rope skipping as an example, after learning the skill and practicing for a period of time, students will inevitably feel bored. In view of the above situation, teachers should think about how to make rope skipping more interesting. For example, they can guide the students to triple jump, double jump, etc. Through interesting ways, they can mobilize students' learning enthusiasm. It does not break away from the teaching of rope skipping, but rather, it makes learning more flexible and vivid ${ }^{[5]}$.

\subsection{Implementation}

Taking the improvement process as an example, under the previous target model, the first thing is to formulate the teaching objectives. For example, in class, how many gymnastics movements should students learn? In practical teaching, teachers would demonstrate the correct movements and explain the key points of the movements. Students would then imitate the teachers. Teachers are responsible for error correction and providing feedback. Although the class efficiency is high, due to the lack of independent thinking process, the teaching lacks vitality, which is not conducive to the cultivation of students' autonomous learning skills. Under the process model, taking gymnastics as an example. Firstly, the general teaching 
objectives are determined. Secondly, creative and flexible teaching activities are carried out. Then, students are required to summarize by themselves. Finally, the teaching results are evaluated. In the process of practice, the teacher can first instruct the students to learn relevant gymnastics movements, such as fish jump and forward roll. In order to stimulate students' interest in learning, the teacher can list out and demonstrate the fish jump of volleyball players and that of goalkeepers in football to enable the students to master the essentials of the movements. After that, the teacher can divide the students into different groups for practice and discussion of the key points under the guidance of the teacher. In this way, students' interest in learning can be mobilized, and at the same time, they would gain a lot of experience and insights.

\section{Conclusion}

This paper mainly explores the middle school physical education curriculum design based on the process model. Compared with the traditional target model, the process model emphasizes more on the cultivation of students' personality and subjectivity. At the same time, it also gives full play to the internal value of the curriculum content and fully highlights the humanistic spirit. Therefore, physical education teachers need to pay more attention to the process model and constantly improve their comprehensive ability and quality, so as to better implement the model and promote the continuous improvement of the quality of middle school physical education.

\section{Disclosure statement}

The authors declare that there is no conflict of interest.

\section{References}

[1] Li H, Xie Y, 2018, Research on the Training Effect of Backbone Physical Education Teachers in Primary and Secondary Schools in China from the Perspective of New Curriculum Standards (Summary). Inner Mongolia Sports Science and Technology, 26(4): 34-74.

[2] Liu M, 2018, Discussion on the Teaching Process Construction and Teaching Behavior of "Sports Education Model" in Senior High School from the Perspective of New Curriculum Reform. New Curriculum Research, 7(6): 44-74.

[3] Qian J, 2018, Teaching Experimental Research on the Implementation of "Learning Plan Guidance" in Junior Middle School Physical Education Under the Background of New Curriculum Reform Taking Wuxi Taying Middle School as an Example, Suzhou University.

[4] Liu M, 2018, Discussion on the Teaching Process Construction and Teaching Behavior of "Sports Education Model" in Senior High School from the Perspective of New Curriculum Reform. New Curriculum Research, 7(6): 19.

[5] Ji T, Yang J, Ji L, 2017, Research on the Interaction Between Top-Level Design and Grass-Roots Exploration of Physical Education Curriculum Reform - Based on the Exploration of Three-Level Management Mode of Physical Education Curriculum. Journal of Chengdu Institute of Physical Education, 6(5): 54-74.

Publisher's note

Bio-Byword Scientific Publishing remains neutral with regard to jurisdictional claims in published maps and institutional affiliations. 